\title{
Isolation and Characterization of Human Umbilical Cord Mesenchymal Stem Cells and Their Differentiation into Pdx-1+ Cells
}

\author{
Mahmoud Hashemitabar 1,2, Elham Allahbakhshi' ${ }^{3}$, Mohamad Reza Tabande ${ }^{4}$, \\ Mahmoud Orazizadeh ${ }^{1,2}$, Fereshteh Nejad Dehbashi'2, Saeed Azandeh ${ }^{1}$, \\ Kambiz Ahmadi Engali5, Darioush Bijan Nejad ${ }^{1,2 *}$ \\ ${ }^{1}$ Department of Anatomical Science, Faculty of Medicine, Ahvaz Jundishapur University of Medical Sciences \\ (AJUMS), Ahvaz, Iran \\ ${ }^{2}$ Cellular and Molecular Research Center (CMRC), Ahvaz Jundishapur University of Medical Sciences (AJUMS), \\ Ahvaz, Iran \\ ${ }^{3}$ Depatment of Biology, Faculty of Sciences, Izeh Branch, Islamic Azad University, Izeh, Iran \\ ${ }^{4}$ Department of Basic Sciences, School of Veterinary Medicine, Shahid Chamran University, Ahvaz, Iran \\ ${ }^{5}$ Department of Statistics and Epidemiology, Faculty of Public Health, Ahvaz Jundishapur University of Medical \\ Sciences (AJUMS), Ahvaz, Iran \\ Email: ${ }^{*}$ daryoshbijan@yahoo.com
}

Received 15 September 2015; accepted 15 November 2015; published 18 November 2015

Copyright (C) 2015 by authors and Scientific Research Publishing Inc.

This work is licensed under the Creative Commons Attribution International License (CC BY). http://creativecommons.org/licenses/by/4.0/

c) (i) Open Access

\section{Abstract}

Background: Recent studies have focused on generating of insulin-producing cells (IPCs) from pluripotent stem cells. Producing of precursor's population with pancreatic endoderm properties is a challenging issue in front of regenerative medicine investigators. Previous studies have shown that during pancrease development in lower portion of foregut, signals from notochord suppress sonic hedgehog (Shh) expression and lead to increase expression of pancreatic duodenal homeobox-1 (Pdx-1) as a marker for pancreatic precursor's cells. Therefore, Shh repression is considered as a critical step in IPCs generation protocols. Objective: Isolation and characterization of human umbilical cord mesenchymal stem cells (HUC-MSCs) is the aim of current study. As well as the role of basic fibroblast growth factor (bFGF) alone and in combination with cyclopamine are investigated in creating cells with Pdx-1 expression ability. Methods: Cells differentiate into definitive endoderm by adding activin A and wnt- $3 \alpha$ into RPMI medium supplemented with for 3 days. At the second stage, the cells are washed with phosphate-buffered saline (PBS). One group (group A) is treated with bFGF for 5 days. Second group (group B) is treated with cyclopamine-KADD for 5 days. Third group (group C) is treated with bFGF and cyclopamine-KAAD for 5 days. Forth group

\footnotetext{
${ }^{*}$ Corresponding author.
}

How to cite this paper: Hashemitabar, M., et al. (2015) Isolation and Characterization of Human Umbilical Cord Mesenchymal Stem Cells and Their Differentiation into Pdx-1 ${ }^{+}$Cells. J. Biomedical Science and Engineering, 8, 780-788. 
(group D) is untreated as control. Result: Our results show that bFGF and cyclopamine in combination induce more expression of Pdx-1 in HUC-MSCs.

\author{
Keywords
}

bFGF, Cyclopamine, Pdx-1, Human Wharton's Jelly

\title{
1. Introduction
}

Human umbilical cord consists of a heterogeneous population of pluripotent stem cells including mesenchymal stem cells derived from mucoid connective tissue (Wharton's jelly) and boon marrow stem cells derived from blood vessels [1]. Human umbilical cord derived mesenchymal stem cells (HUC-MSCs) has characteristics such as self-renewal properties, the ability to differentiate into various lineages with high plasticity [2]. Comparing with other MSCs sources, HUC-MSCs appear to be ideal source because of its availability and non-invasive isolation procedure to donors.

Pancreas is a derivative of definitive endoderm. Recent studies have demonstrated some important signaling pathways such as hedgehog signaling that is involved in regulating pancreatic development [3]. Formation of dorsal pancreas requires sonic hedgehog (Shh) inhibition in the lower portion of foregut [4]. Biological factors like activin $\beta$ B [5] [6] and bFGF [7] repress hedgehoge signaling pathway and promote embryonic stem cells (ESc) into pancreatic fate. bFGF is a member of the fibroblast growth factor family of protein which play various biological activities ranging from proliferation [8] to differentiation [9]. Lumelsky and his college show that bFGF is useful during differentiation of ES cells into IPCs [10]. On the other hand, in 2006, Serafimidis and his college [11] also D'Amour and his co-workers [12] claimed that KAAD-cyclopmina acted as Shh inhibitor and thereby increased the expression of pancreatic duodenal homeobox-1 (Pdx-1) during differentiation of ESc into pancreatic cells [11]. Pdx-1 is a transcription factor that expressed in early stages of development of pancreatic progenitor cells [13]. And it also plays an important role for specification and maturation of $\beta$-cells [14].

According to what have been mentioned above, we decide after exposure of HUC-MSCs with activin A and wnt- $3 \alpha$ to examine the effect of bFGF and cyclopamine alone and in combination in order to generation of cells with ability of expression of Pdx-1.

\section{Material and Methods}

\subsection{Ethic Approval}

The study protocol was approved by the Ethics Committee of Ahvaz Jundishapour University of Medical Sciences (AJUMS) and all procedures were performed according to ethical committee approval.

\subsection{Isolation and Culture of HUC-MSC}

After informed consent of parents, 15 - $20 \mathrm{~cm}$ of umbilical cord close to the placenta were cut and immediately squeezed in order to drain the extra blood. The umbilical cord was placed into 100 - $200 \mathrm{ml}$ transport medium including DMEM-HG (Gibco, cat; 12800 - 058) supplemented with $2 \mathrm{mM} \mathrm{L-Glutamine,} \mathrm{3 \%} \mathrm{(w/v)} \mathrm{Pen/strep}$ (Gibco cat; 15140) and $5 \mu \mathrm{g} / \mathrm{ml}$ amphotericin (sigma cat; A2942) in sterile glass jar with lid and transferred to laboratory at $4{ }^{\circ} \mathrm{C}$. The umbilical cord was washed in PBS (Phosphate Buffer Saline) and cut into smaller pieces (3- $5 \mathrm{~cm}$ ). Amniotic membrane was removed carefully by making a longitudinal incision in each piece and by using a forceps, blood vessels were removed. At the end of this stage, the remaining tissue is Wharton's jelly (WJ). WJ tissue was cut into small pieces, approximately $3-5 \mathrm{~mm}$ in size and $10-20 \mathrm{mg}$ in weight. Border of each pieces of explants were carefully trimmed and washed twice in PBS. 6 - 7 explants pieces transferred to each $25 \mathrm{~cm}^{2}$ culture flask and incubated $5 \mathrm{~min}$. To achieve a better attachment, $3 \mathrm{ml}$ pre warmed DMEM/HG supplemented with 15\% FBS (Fetal Bovine Serum) (Gibco cat; 41G9863K) and L-Glutamine (2 mM) added to each flask as medium were lower the top of pieces. In addition, to prevent shaking that may lead to float of explants pieces the primary culture were incubated at $37^{\circ} \mathrm{C}, 5 \% \mathrm{CO}_{2}$ for $72 \mathrm{~h}$ and after that medium were changed carefully. During 5 - 7 days later, explants buds were observed around pieces (Figure 1). Every other day, the 


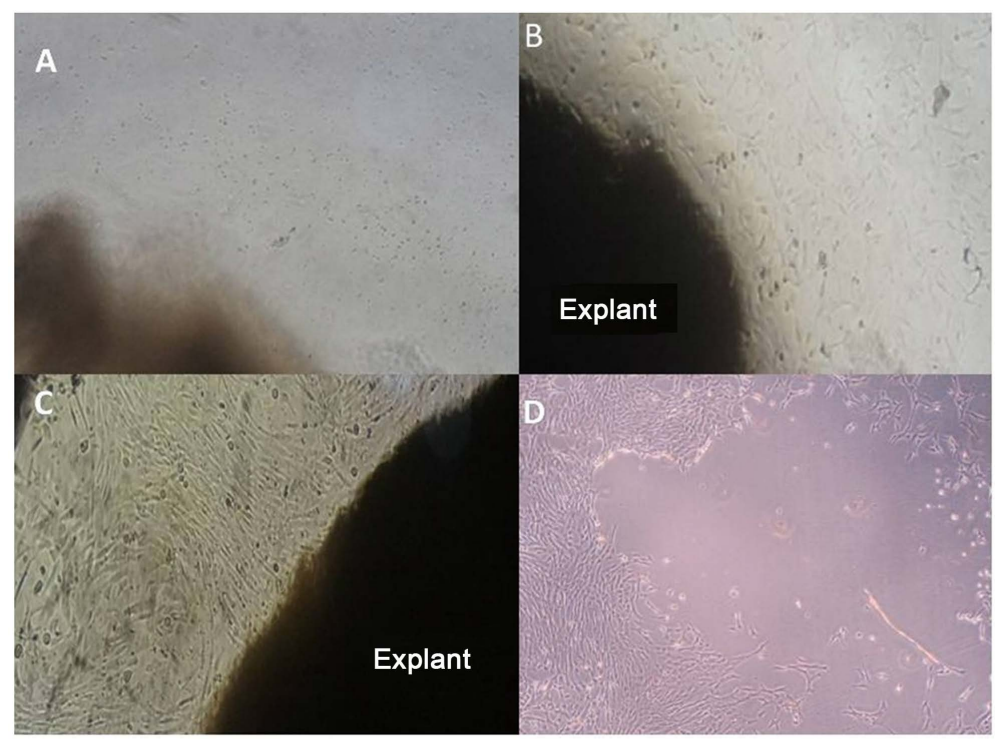

Figure 1. HUC-MSCs migration from explants pieces. (A): 5 days after explant, round shape cells appear around the edge of the explants; (B): 8 days after explants; (C): 10 days after explants; (D): Day 14th after removing explants. All pictures were captured with inverted microscope.

cells were fed with fresh medium for 5 to 8 days following cell migration. The explants pieces were picked up and allowed the cells to achieve more confluence for 3 - 5 days (Figure 1). Migrated cells detached with prewarmed Trypsin-EDTA (Gibco cat; 25300) solution and by adding $6 \mathrm{~mL}$ fresh medium (DMEM/HG with 15\% FBS) to each flask, Trypsin-EDTA solution was neutralized and cell distribution was homogenized (in situ passage; $\mathrm{P}_{0}$, Figure 2(A)). 24 hours later the medium should be changed. Next passages took place at $80 \%-90 \%$ cell confluence.

\subsection{Adipogenic Differentiation}

HUC-MSCs were grown in six-well plates at a density of $3000 \mathrm{cell} / \mathrm{cm}^{2}$ in DMEM-HG media until reaching 90\% confluence. The medium was changed with adipogenic induction medium for 21 days. Adipogenic medium was composed of $50 \mu \mathrm{g} / \mathrm{ml}$ L-ascorbic acide-2-phosphate (sigma, cat; A8960), $100 \mathrm{nM}$ dexametazon (sigma, cat; D4902) and $50 \mu \mathrm{g} / \mathrm{ml}$ indometacin (sigma, cat; I7378) [15]. The adipogenic induction medium was changed every 3 days. After 3 weeks to evaluate the formation of Lipid vacuoles, Oil Red O (Bio-IDEA cat; 03111) staining was used as follow: all induction media was aspirated, each well was washed with $2 \mathrm{ml}$ PBS after and 2 $\mathrm{ml}$ of $10 \%$ Formalin was added to each well then incubated for $25 \mathrm{~min}$ at room temperature in order to cell fixation. After 25 mins the Formalin was aspirated and $2 \mathrm{ml}$ of Oil Red $\mathrm{O}$ working solution was added to each well and after 5 mins, cells were washed indirectly with tap water. Cells were observed using an inverted phase contrast microscope and Lipid-vacuoles were red (Figure 3). As a control sample equal number of cells were cultured in DMEM-HG supplemented with 10\% FBS for 21 days.

\subsection{Osteogenic Differentiation}

HUC-MSCs were differentiated toward the osteogenic linage according to the protocol described by Wang et al. [15]. Mesenchymal stem cells in $\mathrm{P}_{3}$ were cultured in six-well plates at a density of $3000 \mathrm{cells} / \mathrm{cm}^{2}$ in DMEMHG media until reaching $90 \%$ confluence. Osteogenic medium was added to cells for 21 days. Osteogenic induction medium consisted of $10 \mathrm{nM}$ Dexamethazone, $10 \mathrm{nM} \beta$-glycerophosphate (Sigma cat; 50,020), $0.05 \mathrm{nM}$ L-ascorbic acid-2-phosphates and 10\% FBS in DMEM-HG. As a control sample equal number of cells were cultured in DMEM-HG supplemented with 10\% FBS for 21 days. The media were replaced every 4 days in both groups. At the end of 21 days, the cells were stained by Alizarin Red S (sigma cat; A5533) for assessment of calcium deposition and observed under a phase contrast inverted microscope (Figure 3). 


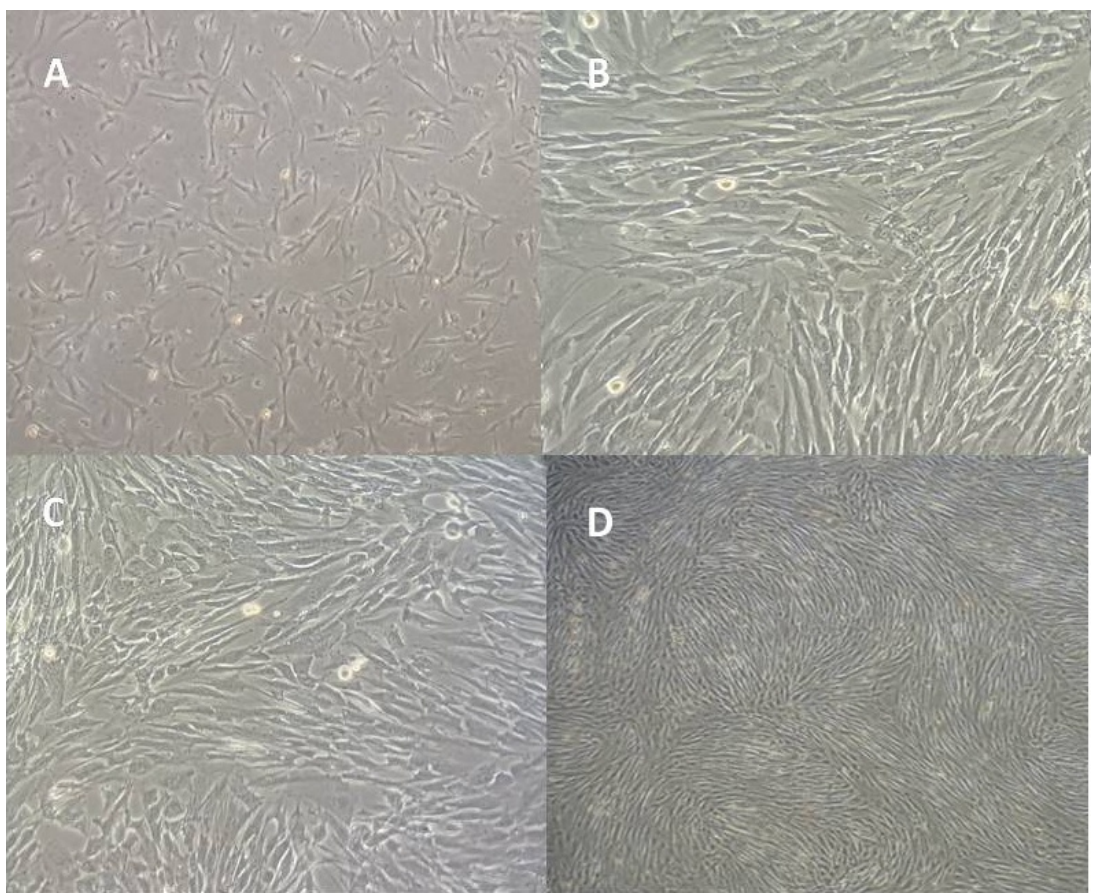

Figure 2. Phase contrast images of human Wharton's jelly mesenchymal stem cells (A): After subculture in situ; (B): After the second passage; (C): After the third passage; (D): After the forth passage with fingerprint like shape when they reach into $100 \%$ confluence.

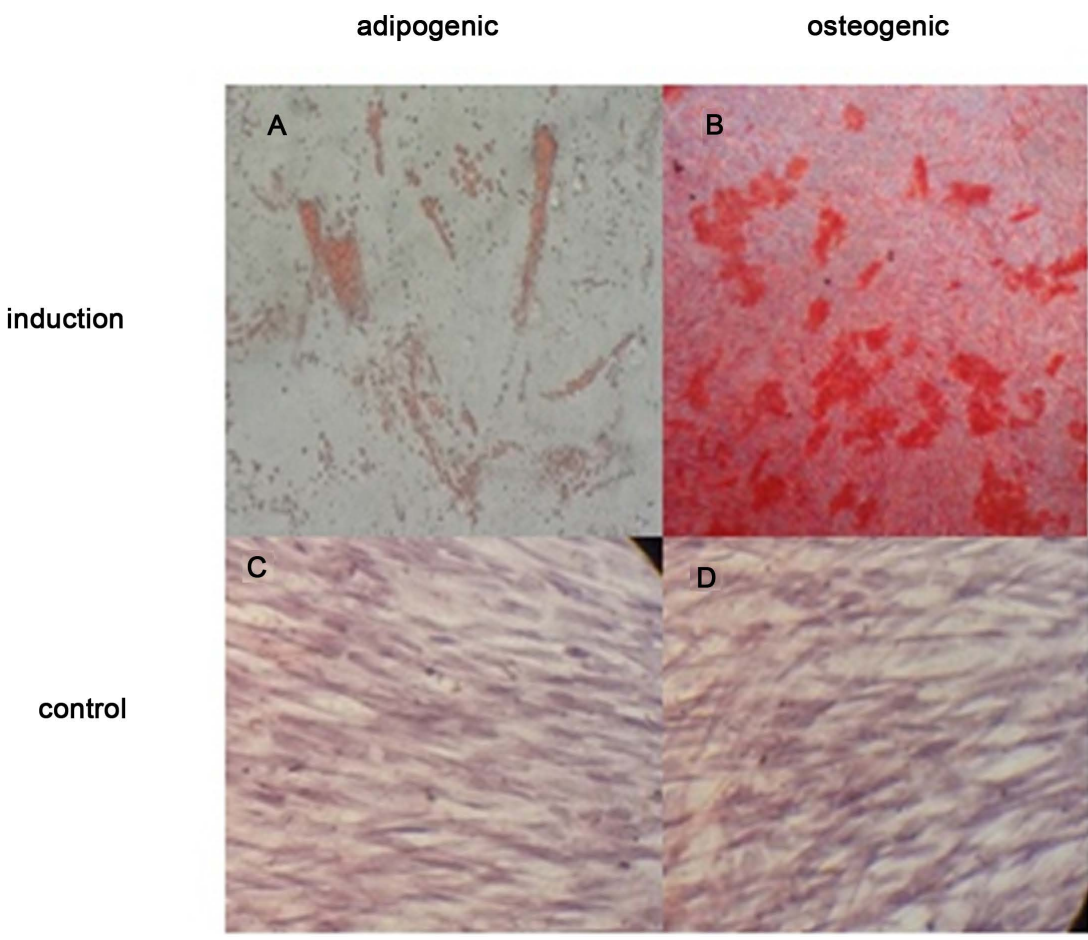

Figure 3. Differentiation of UC-MSC into adipocytes and osteoblasts. After 21 days in adipogenic medium lipid droplets were formed and stained with Oil Red O staining (A) and calcium deposition was stained with Alizrin Red S staining; (B) in osteogenic medium. Non-treated cells were not stained in control groups ((C) \& (D)). 


\subsection{Flow Cytometry}

The isolated HUC-MSCs were trypsinized in passage 3 and transferred into $15 \mathrm{ml}$ Falcon tube. By adding 2 - 3 $\mathrm{ml}$ PBS, cells were centrifuged (5 min, $2000 \mathrm{rpm}$ ). The supernatant was aspirated and PBS supplemented with 5\% FBS added to cell plate and resuspended. The cells were incubated for 30 min at $4^{\circ} \mathrm{C}$ with $5 \mu \mathrm{l}$ anti-human antibodies against CD105 (PE, 12-1057-41), CD90 (FITC, 11-0909-41), CD34 (FITC, 11-0349-41) and CD45 (FITC, 11-9459-41) in dark. All antibodies were purchased from ebioscience. Finally, 1 - $2 \mathrm{ml}$ PBS containing 5\% FBS was added to samples and centrifuged $\left(4^{\circ} \mathrm{C}, 5 \mathrm{~min}, 2000 \mathrm{rpm}\right)$. By adding $1 \mathrm{ml}$ PBS to plates and resusspend the cells samples were assessed using the Dako Galaxy flow cytometry and the data were analyzed using Flowjo software (Figure 4).

\subsection{Differentiation of HUC-MSCs toward Pdx-1+ Cells}

HUC-MSCs were cultured in $25 \mathrm{~cm}^{2}$ flasks and allowed to reach 80\% - 90\% confluence in DMEM-HG medium supplemented with $10 \%$ FBS (v/v). At the first stage, cells differentiated into definitive endoderm by adding activinA (100 ng/ml) (sigma, cat; A4941) and wnt-3 $\alpha$ (25 ng/ml) (sigma, cat; SRP3259) into RPMI medium (Gibco, cat; 51,800 - 019) supplemented with BSA $(0.1 \% \mathrm{v} / \mathrm{v})$ for 3 days. At the second stage, the cells were washed with phosphate-buffered saline (PBS). One group (group A) was treated with bFGF (64 ng/ml) (Millipore, cat; GF003) for 5 days. Second group (group B) was treated with cyclopamine-KADD $(0.25 \mu \mathrm{M})$ (CALBIOCHEM, cat; 299,804) for 5 days. Third group (group C) was treated with bFGF $(64 \mathrm{ng} / \mathrm{ml}$ ) and cyclopamine-KAAD for 5 days. Forth group (group D) was untreated as control. For all groups the medium was also changed from RPMI into DMEM-HG (Gibco). All details about culture condition described in Table 1.
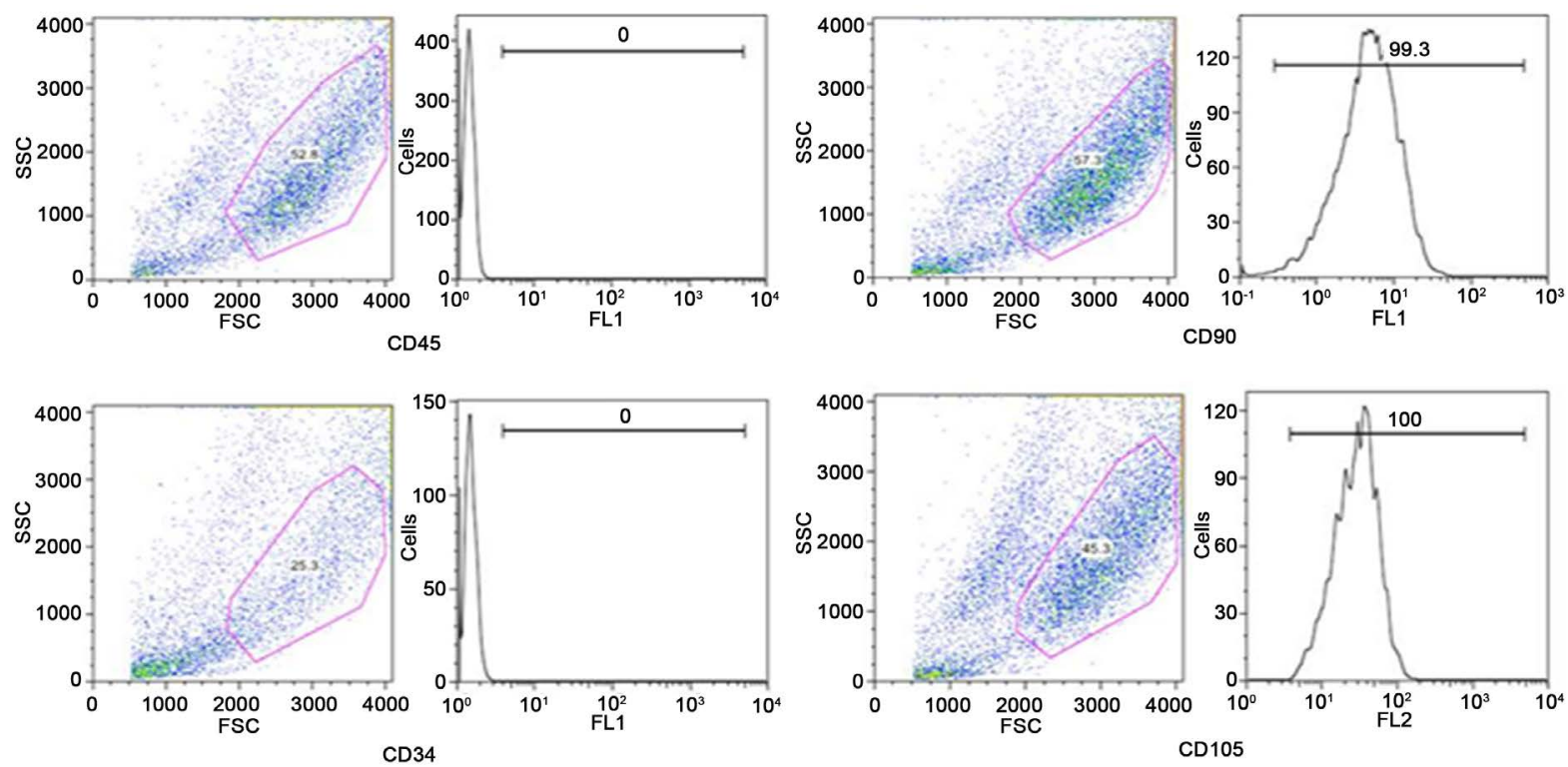

Figure 4. Flow cytometric analysis of Wharton's jelly mesenchymal cell surface antigens. The cells were cultured in DMEM-HG supplemented with 10\% FBS and after three passage were analyzed by flow cytometry. The cells express CD90 and CD105 but do not express CD34 and CD45 (hematopoietic markers).

Table 1. Medium and supplement used for definitive endoderm (DE) and pancreatic endoderm (PE) induction.

\begin{tabular}{|c|c|}
\hline $\begin{array}{c}\text { (First stage) } \\
\text { DE induction; (3 days) }\end{array}$ & $\begin{array}{c}\text { (Second stage) } \\
\text { PE induction (Pdx-1 }{ }^{+} \text {cells); (5 days) }\end{array}$ \\
\hline \multirow{4}{*}{$\begin{array}{c}\text { All groups (A, B, C, D) } \\
\text { RPMI + BSA }(0.1 \% \mathrm{v} / \mathrm{v})+\text { Activin } \\
\text { A }(100 \mathrm{ng} / \mathrm{ml}+\text { wnt-3 } \alpha(25 \mathrm{ng} / \mathrm{ml})\end{array}$} & Group A: DMEM-HG + FBS $(2 \% \mathrm{v} / \mathrm{v})+$ bFGF $(64 \mathrm{ng} / \mathrm{ml})$ \\
\hline & Grope B: DMEM-HG + FBS $(2 \% \mathrm{v} / \mathrm{v})+$ cyclopamine $(0.25 \mu \mathrm{M})$ \\
\hline & Group C: DMEM-HG + FBS (2\%v/v) + bFGF + cyclopamine \\
\hline & Group D (control): DMEM-HG + FBS (2\%v/v) \\
\hline
\end{tabular}




\subsection{RNA Extraction and Real-Time PCR}

At the end of differentiation period (after second stage), cells were tripsinized and collected. Using RNA spin Mini RNA Isolation Kits (Qiagen) total RNA were extracted according to manufacturer's instructions. The total RNA was converted to first strand of cDNA using cDNA synthesis kit (Fermentas, cat; K1622) and oligo (dT) as primers. Real-time PCR assays were performed in douplicat. GAPDH was used as housekeeping control gene. The sequences of primers used for Real-time PCR are listed in Table 2. Power syber green PCR master mix (ABI, cat; 4367659) was used according to manufacturer's instructions. Thermo-cycles condition was: $95^{\circ} \mathrm{C}$ for 10 mins followed by 50 cycles at $95^{\circ} \mathrm{C}$ for 10 seconds, $56^{\circ} \mathrm{C}$ for 30 seconds and $72^{\circ} \mathrm{C}$ for 30 seconds. A nontemplate control was used as a negative control for each gene. Data were analyzed using Livak method (also known as the $2^{-\Delta \Delta \mathrm{Ct}}$ method).

\subsection{Statistical Analysis}

Analysis of VAriance (ANOVA) was used to examine the statistical significance of the differences observed among the treatments. Statistical analysis was performed using SPSS version 14 software (Chicago, IL).

\section{Results}

\subsection{Isolation and Culture of HUC-MSCs}

Explants technique was used to prevent damage caused by mechanical and enzymatic methods. After 5-8 days, cell buds were observed around explants (Figure 1). These cells were adherent. In the following days, the cell morphology was changed from round to monolayer spindle-like shape with a whir pool-like arrangement. We found that after explants pieces discard at 14th day, the cells should be passages in situ to keep cell density and uniform cell distribution. It should be mentioned; our observation showed that cell-cell interaction is so important to maintain cell dividing and viability because in low cell density proliferation and viability decreased (data not shown).

\subsection{Adipogenic and Osteogenic Differentiation of HUC-MSCs}

The cells treated with adipogenic induction medium for 21 days, showed a lot of lipid vacuoles that stained by Oil Red O (Figure 3(A)). While in osteogenic induction medium, deposition of calcium stained as red color by Alizarin Red (Figure 3(B)). In non-treated control cells, no mineralized matrix and lipid vacuole were observed (Figure 3(C) \& Figure 3(D)).

\subsection{Flow Cytometry}

Flow cytometric analysis indicated high level expression of mesenchymal cell surface markers (CD 105 and CD 90) but not expression of hematopoietic markers (CD34, CD45) in the mesenchymal stem cells of Wharton's jelly.

\subsection{Pdx-1 Gene Expression}

Real-time analysis showed that Foxa2 and Sox17 were upregulated in cells when treated with activin A and wnt3- $\alpha$ (data not shown). Our results also showed that Pdx-1 had peak expression in cells treated with bFGF and cyclopamine in combination, in comparison with other groups (Figure 5).

Table 2. List of primer sequences used for real-time PCR.

\begin{tabular}{ccc}
\hline Gene & Primer sequences & Annealing temperature $\left({ }^{\circ} \mathrm{C}\right)$ \\
\hline PDX-1 & $\begin{array}{c}\text { Forward (5' GGA TGA AGT CTA CCA AAG CTC ACG C 3') } \\
\text { Reverse (5’ CCA GAT CTT GAT GTG TCT CGG TC 3') }\end{array}$ & 58 \\
GAPDH & Forward (5’ TGG TAT CGT GGA AGG ACT CA 3') \\
& Reverse (5’ CCT GCT TCA CCA CCT TCT TG 3') \\
\hline
\end{tabular}




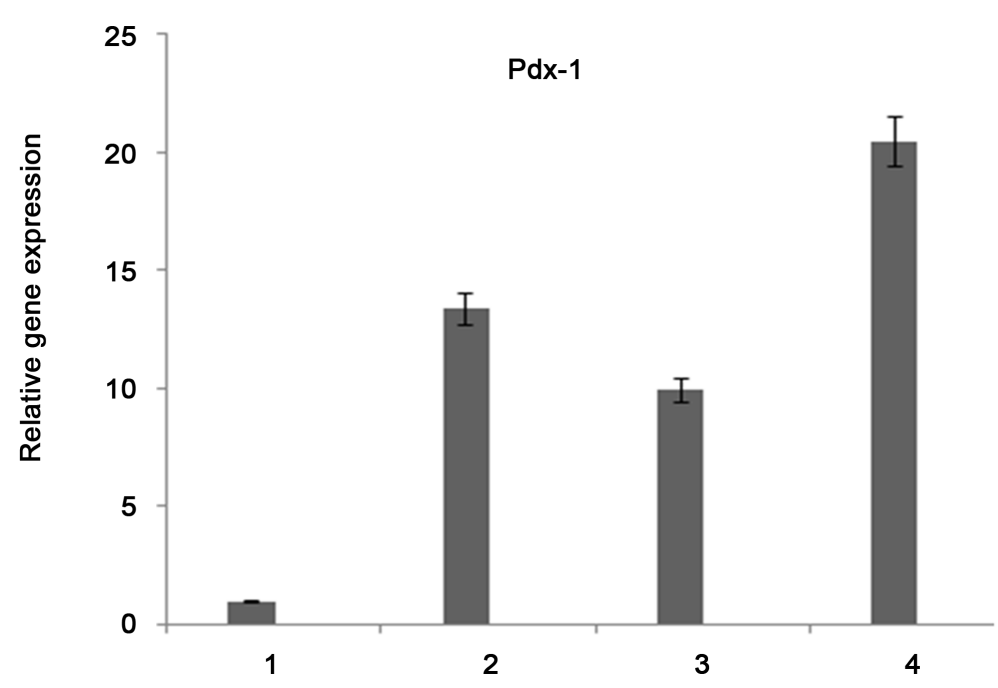

Figure 5. Pdx-1 expression increased in sample treated by cyclopamine (2) in compared with bFGF (3). But Pdx-1 expression was significantly up regulated in sample treated by bFGF and cyclopamine (4) in combination. 1 = no factor. All treatment was performed in triplicate.

\section{Discussion}

Recent efforts have focused to find new sources of stem cells for therapeutic purposes. Previously the umbilical cord has been discarded during labor, but now it can be consider as a rich source of mesenchymal stem cells [2] [16]. This study addresses the pluripotency of HUC-MSCs by assessment of their differentiation into different linage such as adipocyte and osteocyte. Also it emphasizes on simplicity and safety of explants method because it is based on migration properties of HUC-MSCs from explants borders unlike enzymatic method, which may be harmful for cell viability. Cell surface marker analysis demonstrated that HUC-MSCs are positive for mesenchymal stem cell markers (CD90, CD105) and negative for hematopoetic stem cell markers (CD34, CD45).

During recent years, there is a tremendous interest in generating of $\mathrm{Pdx}-1^{+}$cells from human pluripotent stem cells [17]. Pdx-1 is a key transcription factor involved in islet $\beta$ cell function and pancreatic development and express in pancreatic endoderm [17] [18]. It also plays a crucial role in the initiation of pancreatic endocrine cell differentiation from primitive cells and is therefore considered a master switch of pancreatic differentiation [14] [19].

Some studies also suggest that repression of sonic hedgehog in the lower portion of foregut leads to formation of Pdx $-1^{+}$cells population in this region [3]. During pancreace development secretion of activin $\beta \mathrm{B}$ and bFGF from notochord have an important role in repression of sonic hedgehog, thereby permitting expression of Pdx-1 [20].

Several evidences from previous studies suggested bFGF as Shh repressor some of them also have shown that intermediate concentration of exogenous bFGF differentiate human embryomic stm cell toward pancreatic fate by expression of Pdx-1 [9] [21]. They demonstrated that bFGF via activation of MAPK signaling pathway induces Pdx-1 expression. Among differentiation protocol to producing IPCs, KAAD-cyclopamine also have been extensively used as a pancreatic endoderm inducer [12]. These investigators showed that KAAD-cyclopamine act by block smo as a receptor of sonic hedgehog signaling pathway. D'Amour and coworkers after definitive endoderm induction used FGF10 in combination with KAAD-cyclopamine to creating Pdx $-1^{+}$cells, but we replace FGF10 by bFGF in this stage. According to what have been described, our results show that Pdx-1 expression is highly up regulated using bFGF and KAAD-cyclopamine in combination and it can be somewhat justified that these factors synergistically act together in Shh suppression and thereby increase the expression of Pdx- 1 . But more investigations need to be clarifying the exact mechanisem by which bFGF and KAAD-cyclopamine work together.

\section{Conclusion}

This study described a simplified isolation method for HUC-MSCs. We could also conclude that bFGF and 
cycloamin together led to more expression of Pdx-1 and this finding could be helpful in differentiation protocols in order to access pancreatic endoderm for cell therapy aims.

\section{Acknowledgements}

This work is a part of PhD thesis of Darioush Bijan Nejad. This work was supported by the Cellular and Molecular Research Center (CMRC), Ahvaz Jundishapour University of Medical Sciences. We also thank from Obstetrics and Gynaecology physicians of Imam Khomeini hospital of Ahvaz.

\section{References}

[1] Troyer, D.L. and Weiss, M.L. (2008) Concise Review: Wharton's Jelly-Derived Cells Are a Primitive Stromal Cell Population. Stem Cells, 26, 591-599. http://dx.doi.org/10.1634/stemcells.2007-0439

[2] Fong, C.Y., Subramanian, A., Biswas, A., Gauthaman, K., Srikanth, P. and Hande, M.P. (2010) Derivation Efficiency, Cell Proliferation, Freeze-Thaw Survival, Stem-Cell Properties and Differentiation of Human Wharton's Jelly Stem Cells. Reprod Biomed Online, 21, 391-401. http://dx.doi.org/10.1016/j.rbmo.2010.04.010

[3] Hebrok, M., Kim, S.K. and Melton, D.A. (1998) Notochord Repression of Endodermal Sonic Hedgehog Permits Pancreas Development. Genes and Development, 12, 1705-1713. http://dx.doi.org/10.1101/gad.12.11.1705

[4] Kawahira, H., Scheel, D.W., Smith, S.B., German, M.S. and Hebrok, M. (2005) Hedgehog Signaling Regulates Expansion of Pancreatic Epithelial Cells. Developmental Biology, 280, 111-121. http://dx.doi.org/10.1016/j.ydbio.2005.01.008

[5] Frandsen, U., Porneki, A.D., Floridon, C., Abdallah, B.M. and Kassem, M. (2007) Activin B Mediated Induction of Pdx-1 in Human Embryonic Stem Cell Derived Embryoid Bodies. Biochemical and Biophysical Research Communications, 362, 568-574. http://dx.doi.org/10.1016/j.bbrc.2007.07.200

[6] Ku, H.T., Zhang, N., Kubo, A., O’Connor, R., Mao, M., Keller, G. and Bromberg, J.S. (2004) Committing Embryonic Stem Cells to Early Endocrine Pancreas in Vitro. Stem Cells, 22, 1205-1217. http://dx.doi.org/10.1634/stemcells.2004-0027

[7] Shi, Y., Hou, L., Tang, F., Jiang, W., Wang, P., Ding, M. and Deng, H. (2005) Inducing Embryonic Stem Cells to Differentiate into Pancreatic Beta Cells by a Novel Three-Step Approach with Activin A and All-Trans Retinoic Acid. Stem Cells, 23, 656-662. http://dx.doi.org/10.1634/stemcells.2004-0241

[8] Cheng, Y., Tao, Y., Black, I.B. and DiCicco-Bloom, E. (2001) A Single Peripheral Injection of Basic Fibroblast Growth Factor (bFGF) Stimulates Granule Cell Production and Increases Cerebellar Growth in Newborn Rats. Journal of Neurobiology, 46, 220-229. http://dx.doi.org/10.1002/1097-4695(20010215)46:3<220::AID-NEU1004>3.0.CO;2-P

[9] Fogarty, M.P., Emmenegger, B.A., Grasfeder, L.L., Oliver, T.G. and Wechsler-Reya, R.J. (2007) Fibroblast Growth Factor Blocks Sonic Hedgehog Signaling in Neuronal Precursors and Tumor Cells. Proceedings of the National Academy of Sciences of the United States of America, 104, 2973-2978. http://dx.doi.org/10.1073/pnas.0605770104

[10] Lumelsky, N., Blondel, O., Laeng, P., Velasco, I., Ravin, R. and McKay, R. (2001) Differentiation of Embryonic Stem Cells to Insulin-Secreting Structures Similar to Pancreatic Islets. Science, 292, 1389-1394. http://dx.doi.org/10.1126/science.1058866

[11] Serafimidis, I., Rakatzi, I., Episkopou, V., Gouti, M. and Gavalas, A. (2008) Novel Effectors of Directed and Ngn3Mediated Differentiation of Mouse Embryonic Stem Cells into Endocrine Pancreas Progenitors. Stem Cells, 26, 3-16. http://dx.doi.org/10.1634/stemcells.2007-0194

[12] Kevin, A.D.A., Anne, G.B., Susan, E., Olivia, G.K., Alan, D.A., Nora, G.S., Mark, A.M., Evert, K., Melissa, K.C. and Emmanuel, E.B. (2006) Production of Pancreatic Hormone-Expressing Endocrine Cells from Human Embryonic Stem Cells. Nature Biotechnology, 24, 1392-1401. http://dx.doi.org/10.1038/nbt1259

[13] Kawaguchi, Y., Cooper, B., Gannon, M., Ray, M., MacDonald, R.J. and Wright, C.V. (2002) The Role of the Transcriptional Regulator Ptf1a in Converting Intestinal to Pancreatic Progenitors. Nature Genetics, 32, 128-134. http://dx.doi.org/10.1038/ng959

[14] Kaneto, H., Matsuoka, T.A., Miyatsuka, T., Kawamori, D., Katakami, N. and Yamasaki, Y. (2008) PDX-1 Functions as a Master Factor in the Pancreas. Frontiers in Bioscience, 13, 6406-6420. http://dx.doi.org/10.2741/3162

[15] Wang, H.S., Hung, S.C., Peng, S.T., Huang, C.C., Wei, H.M., Guo, Y.J., Fu, Y.S., Lai, M.C. and Chen, C.C. (2004) Mesenchymal Stem Cells in the Wharton's Jelly of the Human Umbilical Cord. Stem Cells, 22, 1330-1337. http://dx.doi.org/10.1634/stemcells.2004-0013

[16] Mitchell, K.E., Weiss, M.L., Mitchell, B.M., Martin, P., Davis, D. and Morales, L. (2003) Matrix Cells from Wharton’s Jelly form Neurons and Glia. Stem Cells, 21, 50-60. http://dx.doi.org/10.1634/stemcells.21-1-50 
[17] Thomas, M.K., Lee, J.H., Rastalsky, N. and Habener, J.F. (2001) Hedgehog Signaling Regulation of Homeodomain Protein Islet Duodenum Homeobox-1 Expression in Pancreatic Beta-Cells. Endocrinology, 142, 1033-1040.

[18] D’Amour, K.A., Agulnick, A.D., Eliazer, S., Kelly, O.G., Kroon, E. and Baetge, E.E. (2005) Efficient Differentiation of Human Embryonic Stem Cells to Definitive Endoderm. Nature Biotechnology, 23, 1534-1541. http://dx.doi.org/10.1038/nbt1163

[19] Melloul, D. (2004) Transcription Factors in Islet Development and Physiology: Role of PDX-1 in Beta-Cell Function. Annals of the New York Academy of Sciences, 1014, 28-37. http://dx.doi.org/10.1196/annals.1294.003

[20] Apelqvist, E., Ahlgren, U. and Edlund, H. (1997) Sonic Hedgehog Directs Specialized Mesoderm Differentiation in the Intestine and Pancreas. Current Biology, 7, 801-804. http://dx.doi.org/10.1016/S0960-9822(06)00340-X

[21] Jacqueline, A., Anders, S.H., Jesper, P., Jenny, K.J., Martina, M., Isabella, A. and Henrik, S. (2010) FGF2 Specifies hESC-Derived Definitive Endoderm into Foregut/Midgut Cell Lineages in a Concentration-Dependent Manner. Stem Cells, 28, 45-56.

\author{
Abbreviations \\ IPCs: Insulin-producing cells \\ HUC-MSCs: Human umbilical cord mesenchymal stem cells \\ bFGF: Basic fibroblast growth factor \\ Pdx-1: Pancreatic duodenal homeobox-1 \\ FBS: Fetal bovine serum \\ PBS: Phosphate buffer saline \\ Shh: Sonic hedgehog \\ Wharton's jelly: WJ \\ Pen/Strep: Penicillin/Streptomycin
}

